\title{
Calculation of Iron Losses in Inverter-fed Induction Motors based on Time-stepping FEM
}

\author{
Hai-Rong Wang *, and Jian-Hua Wu **
}

\begin{abstract}
This paper presents a method for calculating iron losses in three-phase induction motors under the inverter supply through the field-circuit coupled time-stepping finite element method (FEM). Iron losses are calculated by using the three-term iron losses separated model and modifying the loss coefficients obtained by the iron losses curves which are provided by the manufacturer under the sinusoidal supply. Simulation results by the presented method are verified by the measured results with an error lower than $5 \%$, confirming the validity of the proposed method. Finally, iron losses distribution of the inverter-fed three-phase induction prototype motor is shown.
\end{abstract}

\section{Keywords: Filed-circuit coupled, FEM, Iron losses, Inverter-fed induction motor}

\section{Introduction}

In recent years, motors supplied by inverters have developed rapidly with the development of manufacturing technology in power electronics devices. And more and more machines use the inverter power supply aiming at realizing the various and complex control of machines. It is well known that inverter-fed motors contain many harmonics which can cause magnetic field waveform in cores produce serious distortion. Consequently, the method of calculating iron losses in motors with sinusoidal supply is no longer applicable. However, it is very important to obtain precise calculation and distribution of iron losses in inverter-fed motors for improving the efficiency of the motor. Therefore the study of iron losses has important theoretical significance and practical value.

Many effective models of iron losses in the ferromagnetic materials under the non-sinusoidal supply have been presented by a great many researchers recently [1-2]. Currently, the research of iron losses in non-sinusoidal supplied machines attracts an increasing attention. Ruiming Fang provides harmonic equivalent circuit model to calculate iron losses based on the harmonic analysis method; however, the accuracy of the result depends on experimental parameters [3]. Qiansheng Hu presents an analytical method of predicting iron losses considered the influences of

College of Electrical Engineering, Zhejiang University, China. (braver704@126.com)

** College of Electrical Engineering, Zhejiang University, China. (emcad@163.com)

Received 08 July 2013; Accepted 20 August 2013 inverter parameters, but it's not a general method [4]. Predicting iron losses under the non-sinusoidal supply by using the relation between the non-sinusoidal and sinusoidal supply is presented by Boglietti. Though this method has a good engineering applicability, the iron losses computed is lower than the value obtained by the measures because of neglecting the excess iron loss [5-6]. The most popular approach is based on FEM due to its accuracy calculation and the simplicity of obtaining iron losses distribution though a relatively complex [7-9]. For this reason, FEM has a unique advantage in the motor design stage.

This paper presents a method for calculating iron losses by modifying loss coefficients of the iron losses based on the separated iron losses model and FEM. Finally, the validity of the proposed method has been proved on an inverter-fed induction prototype motor. The comparison between the measured and calculated iron losses with the inverter supply has shown an excellent agreement.

\section{Calculation Model}

\subsection{Time-stepping FEM}

Table 1 shows the brief specifications of the model analyzed. In order to calculate more conveniently, we can make the following assumptions when analyzing the magnetic field in motors:

(1) The magnetic field in motors is along the axial direction and the end effect can be ignored.

(2) The external leakage magnetic field of the stator core is ignored. 
A three-phase induction motor with the squirrel-cage rotor (shown as Fig. 1) is chosen for 2D finite element analysis model, and the governing equation can be given by (1).

Table 1. Brief Specifications of the three-phase induction motor

\begin{tabular}{|c|c|c|c|}
\hline Item & value & Item & Value \\
\hline Phase number & 3 & Core length(mm) & 95 \\
\hline Pole number & 4 & Outer diameter of stator(mm) & 155 \\
\hline Rated voltage(V) & 220 & Inner diameter of stator $(\mathrm{mm})$ & 98 \\
\hline Rated power(kW) & 1.5 & Outer diameter of rotor $(\mathrm{mm})$ & 97.4 \\
\hline Rated speed(rpm) & 1436 & Outer diameter of rotor(mm) & 38 \\
\hline Frequency $(\mathrm{Hz})$ & 50 & Electrical steel sheets & $50 \mathrm{W600}$ \\
\hline
\end{tabular}

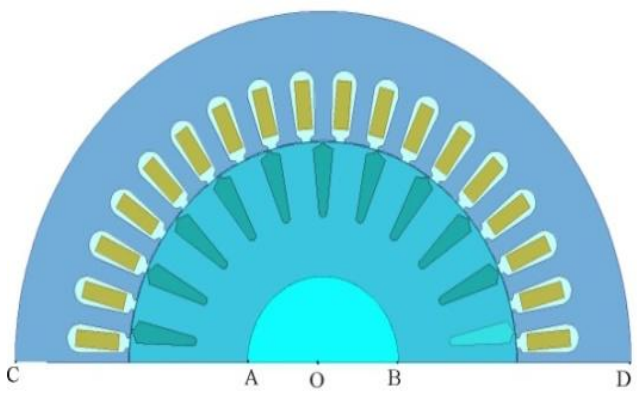

Fig. 1. Induction motor FEM analysis model

$$
\left\{\begin{array}{l}
\Omega: \frac{\partial}{\partial x}\left(\frac{1}{\mu} \frac{\partial A_{Z}}{\partial x}\right)+\frac{\partial}{\partial y}\left(\frac{1}{\mu} \frac{\partial A_{Z}}{\partial y}\right)=-J_{Z}+\sigma \frac{\partial A_{Z}}{\partial t}+\sigma V_{x} \frac{\partial A_{Z}}{\partial x} \\
\left.\Gamma_{1:} A_{Z}\right|_{\overparen{A B}}=\left.A_{Z}\right|_{\overparen{C D}}=0 \\
\left.\Gamma_{2:} A_{Z}\right|_{O C}=\left.A_{Z}\right|_{O D}
\end{array}\right.
$$

where, $\mathrm{A}_{\mathrm{Z}}$ is the $\mathrm{Z}$-component of magnetic vector potential, $\mu$ is the permeability, $\sigma$ is the conductivity of the material, $\mathrm{J}_{\mathrm{Z}}$ is the exciting current density of the stator winding, $\sigma \partial \mathrm{A}_{\mathrm{Z}} / \partial \mathrm{t}$ is the eddy current density of the rotor squirrel-cage bar as well as the ferromagnetic materials area, $\Gamma_{1}$ are the outer surface of the stator and the inner surface of the rotor in which $\mathrm{A}_{\mathrm{Z}}$ meet the first homogeneous boundary condition, $\Gamma_{2}$ are two boundary lines (OC and OD) in which $\mathrm{A}_{\mathrm{Z}}$ meet the periodic homogeneous boundary condition.

The voltage equation per each phase of the stator winding is described as follows:

$$
u=R_{e} i_{s}+L_{e} \frac{d i}{d t}+\frac{d \psi}{d t}
$$

where, $u, R_{e}, i_{s}$, and $\psi$ are the input voltage, the resistance, the current, and the flux linkage of stator each phase, respectively. $L_{e}$ is the end-coil inductance calculated by equivalent method[12].

In induction motors, the currents in rotor bars are generated by the change of vector potential. For the $k^{\text {th }}$ conductor of the rotor, the current restraint equation is expressed as:

$$
i_{r k}=\sum_{n=1}^{\mathrm{N}}\left(-\sigma \frac{\partial A_{Z}}{\partial t}+\sigma \frac{u_{r b, k}}{L_{f e}}\right) S_{k, n}
$$

where, $\mathrm{i}_{\mathrm{rk}}$ and $\mathrm{u}_{\mathrm{rb}, \mathrm{k}}$ are the current and voltage in the $\mathrm{k}^{\text {th }}$ conductor of the rotor, respectively. $\mathrm{N}$ is total number of elements in the $\mathrm{k}^{\text {th }}$ conductor, $\mathrm{L}_{\mathrm{fe}}$ is the linear length of the $\mathrm{k}^{\text {th }}$ conductor, $\mathrm{S}_{\mathrm{k}, \mathrm{n}}$ is the area of the $\mathrm{n}^{\text {th }}$ element's section in the $\mathrm{k}^{\text {th }}$ conducting bar.

The equation of rotary motion in the rotor can be written as:

$$
J \frac{d \Omega}{d t}=T_{e m}-T_{\text {load }}-T_{m, \text { loss }}
$$

in which, $\Omega, J$ are the mechanical velocity and moment of inertia in the rotor, respectively. $T_{e m}, T_{\text {load }}$, and $T_{m, l o s s}$ are the electromagnetic torque, load torque, and torque which is caused by the wind friction loss, respectively.

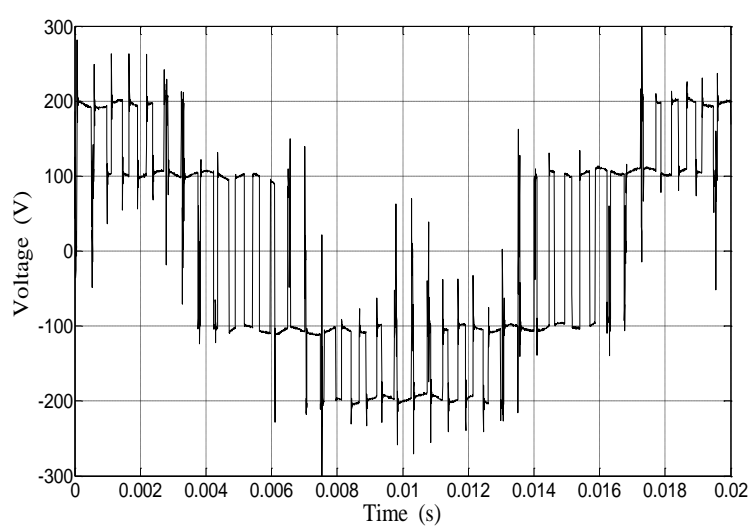

Fig. 2. Experimental waveform of the inverter-fed motor's phase voltage

Starting from (2) to (4), the magnetic vector potential and flux density can be obtained. Meanwhile, the current of stator and rotor can also be acquired. In order to imitate the actual running state of the inverter-fed motor accurately, the experimental waveform data of the inverter's output voltage is used in the process of the simulation. The experimental waveform of the inverter-fed motor's output phase voltage 
is shown as Fig. 2. Fig. 3 is the spectral analysis of the output phase-voltage in the motor when fundamental frequency is $50 \mathrm{~Hz}$ and carrier frequency is $2 \mathrm{k} \mathrm{Hz}$. We can see from Fig. 3: voltage harmonic components which near integer times of carrier frequency are higher.

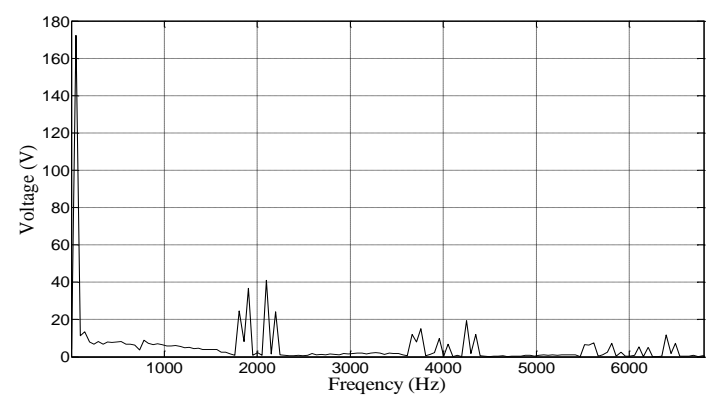

Fig. 3. Spectrum analysis of the inverter-fed motor

\subsection{Calculation of Iron Losses}

A great many of iron losses calculation models have been put forward in a lot of literature. However, in the aspect of calculating iron losses, especially for how to handle the rotation magnetization and non-sinusoidal supply accurately, there are still no mature methods so far. In this paper, we use the conventional three-term iron losses model presented by Bertotti [13]. The model is shown as follows:

$$
\begin{aligned}
& P_{f e}=P_{h}+P_{e}+P_{a} \\
& =k_{h} f K\left(B_{m}\right) B_{m} x+k_{e} f \int_{0}^{T}\left[\frac{d(B(t))}{d t}\right]^{2} d t \\
& +k_{a} f \int_{0}^{T}\left|\frac{d(B(t))}{d t}\right|^{1.5} d t \quad(\mathrm{~W} / \mathrm{kg})
\end{aligned}
$$

where $P_{h}, P_{e}$, and $P_{a}$ are the hysteresis loss, eddy current loss, and excess loss per weight, respectively. $k_{h}, k_{e}$, and $k_{a}$ are the corresponding coefficients of the losses above respectively, $B_{m}$ and $B(t)$ are the maximum and instantaneous flux densities during the time period, respectively, $K\left(B_{m}\right)$ is the coefficient of the local magnetic hysteresis loss, $f$ is the frequency.

Making reference to the ideal winding without the winding losses, the voltage of the winding can be written as:

$$
u(t)=N S \frac{d B(t)}{d t}
$$

where, $N$ is the turn number, $S$ is the section of the magnetic core. If the $u(t)$ is alternate and the instantaneous value has the same sign with the first harmonic component, meanwhile, neglecting the minor loops in the hysteresis loop, we can deduce the following equation:

$$
\int_{0}^{T}|u(t)| d t=4 N S B_{m}
$$

while the voltage $u(t)$ is sinusoidal, we can obtain iron losses as follows:

$$
P_{f e}=k_{h} f B_{m}^{x}+k_{e} f^{2} B_{m}^{2}+k_{a} f^{1.5} B_{m}^{1.5}
$$

where $x$ is $2, k_{e}=\pi^{2} \gamma d^{2} / 6, \gamma$ is the conductivity of the materials, $d$ is the thickness of the electrical steel sheet, $k_{h}$ and $k_{e}$ can be got by fitting the measured loss data of the steel sheet.

The coefficients of the steel presented by silicon steel standard or enterprises are all the data which obtained under the sinusoidal supply condition. In this case, it is not proper to use (8) to calculate the iron losses with the inverter supply directly. Consequently, we use the terminal voltage waveform of the motor and modify the coefficients shown as (8), then we can deduce iron losses model which is proper to calculate iron losses of inverter-fed motors.

While the voltage $u(t)$ is non-sinusoidal, the voltage can be decomposed into a series of harmonic components. Then the flux density corresponding to the $i^{\text {th }}$ voltage harmonic component can be described as:

$$
B_{i}(t)=\frac{1}{2 \pi N S} \frac{v_{i, \max }}{i f} \sin \left(2 \pi i f t+\varphi_{n}\right)
$$

where, $\mathrm{v}_{i, \max }$ is the maximum value of the $i^{\text {th }}$ voltage harmonic component.

The hysteresis loss and eddy current loss of the ferromagnetic material under the non-sinusoidal supply can be considered equal to the sum of the hysteresis loss and eddy current loss under all the voltage harmonic components of the non-sinusoidal supply. Considering there is only a small difference between the sinusoidal and non-sinusoidal supply about the excess loss, consequently, we assume that the excess loss under the non-sinusoidal supply is equal to which under sinusoidal supply condition. Starting from (5) to (9), we can conclude that iron losses can be expressed as:

$$
P_{f e}=k_{h}{ }^{\prime} f B_{m}{ }^{x}+k_{e}{ }^{\prime} f^{2} B_{m}{ }^{2}+k_{a}{ }^{\prime} f^{1.5} B_{m}{ }^{1.5}
$$

where $k_{h}{ }^{\prime}=k_{h} \eta^{2}, k_{e}{ }^{\prime}=k_{e} \chi^{2}, k_{a}{ }^{\prime}=k_{a}, \eta=V_{a v} / V_{a v, 1}$, $\chi=V_{r m s} / V_{r m s, 1}, V_{a v}$ and $V_{r m s}$ are the mean rectified and rms of voltage value, respectively, $V_{a v 1}$ and $V_{r m s 1}$ are the 
mean rectified and $\mathrm{rms}$ of fundamental voltage value, respectively.

\subsection{Measurement of Iron Losses}

The measurement of iron losses can be carried out by making reference to the standard IEEE 112B. The additional loss and copper loss of the rotor in the no-load condition are neglected, and then the power balance equation is imposed as follows:

$$
P_{\text {no-load }}=P_{f e}+P_{c u 1}+P_{\text {mec } 0}
$$

where $P_{n o-l o a d}$ is the absorbed electrical power, $P_{f e}$ is iron losses, $P_{c u 1}$ is the copper loss of stator, $P_{m e c 0}$ is the mechanical loss in the no-load condition. The curve of $P_{f e}+P_{\text {mec } 0}$ with $\left(U_{o} / U_{N}\right)^{2}$ is presented through a set of no-load tests. We can separate the wind friction loss by extending the linear part of the curve. Finally, iron losses can be obtained. The schematic diagram of the experiment device is shown as Fig. 4. Fig. 5 is experimental platform.

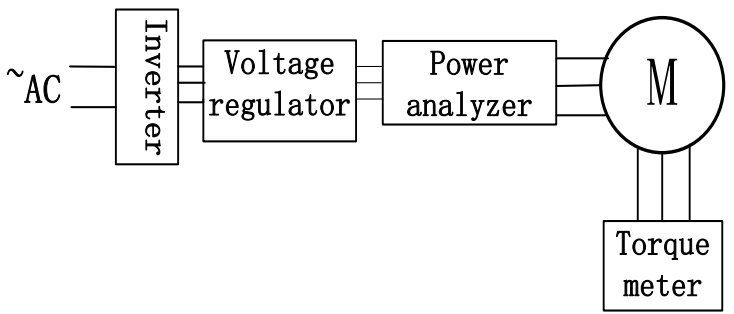

Fig. 4. Experiment device schematic diagram

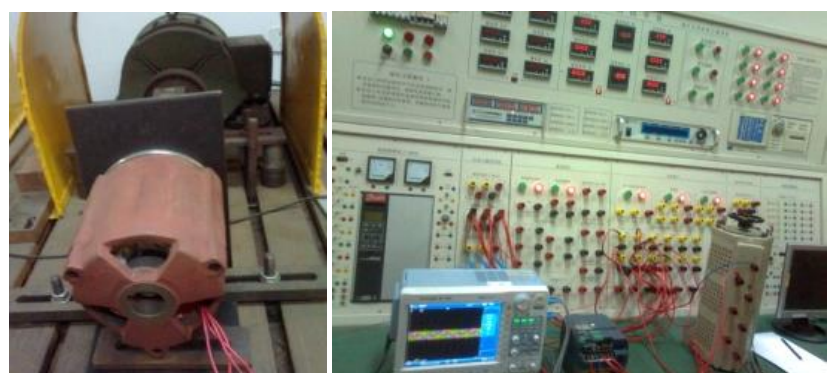

Fig. 5. Experimental platform

\section{The Analysis of Simulation and Experiment}

Iron losses in the motor are various periodically. Fig. 6 is the motor iron losses in a period. Consequently, iron losses in the motor should be the average value in a period. The tests on the prototype motor with the inverter supply have been performed using a constant fundamental frequency of $50 \mathrm{~Hz}$ and switching frequency of $2 \mathrm{kHz}$. Fig. 7 shows the comparison between the calculated and measured iron losses in the three-phase cage squirrel motor with the inverter supply. Iron losses under the sinusoidal supply are also shown in Fig. 7.

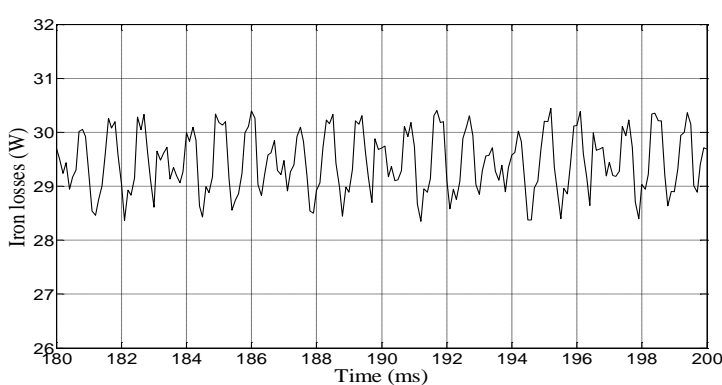

Fig. 6. Iron losses in a period

We can see that iron losses in the motor under the inverter supply are apparently higher than which under the sinusoidal supply, in the range of 20.4 34.3\%. A good agreement between the measured and the calculated iron losses in the motor under inverter supply is well evident. We also can see that the simulation value is a small lower than the measured. There are two major reasons. One is that the experimental value includes the losses of the rotor conductors and the additional loss in the no-load condition, while there are only iron losses included in the calculated. The other is that the calculated iron losses neglect the local hysteresis loss.

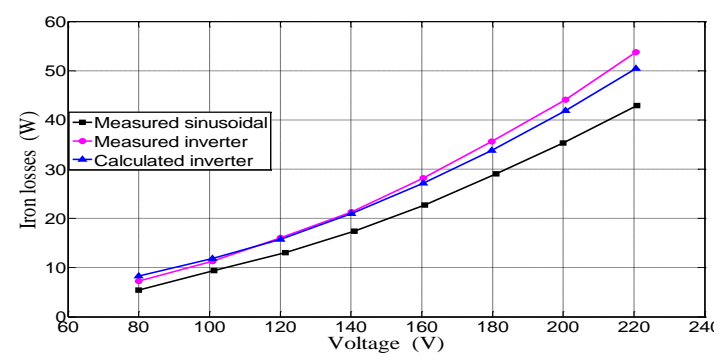

Fig. 7. The measured and calculated iron losses in the prototype motor

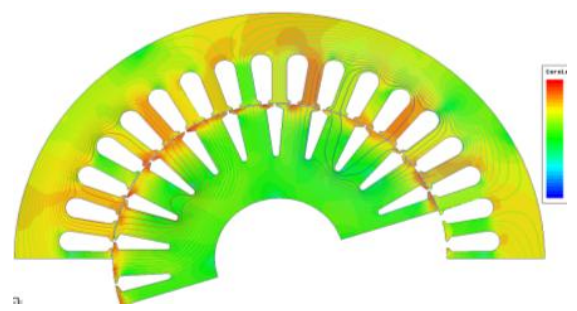

Fig. 8. Distribution of iron losses in the motor

Fig. 8 shows the distribution of iron losses in the three-phase cage squirrel motor under the non-sinusoidal supply condition. The highest iron loss density is predicted in the areas of teeth and teeth-tip in the stator region. And 
iron losses density in the rotor-teeth tip is also very high. We should cause enough attention in inverter-fed motors design stage.

\section{Conclusion}

In this paper, a method of modifying loss coefficients based on iron losses model presented by Bertotti is used to calculate iron losses in inverter-fed motors. The experimental results have proved the method validity, with a good agreement between the calculated and measured iron losses under the inverter supply. The iron losses density in the area of the teeth and teeth-tips in the stator as well as the rotor teeth tips are relatively high in the inverter-fed motors. For that matter, it needs to be paid enough attention in the motors design stage.

\section{Acknowledgements}

This work was supported by the National High Technology Research and Development Program of China 863 (2011AA11A101)

\section{References}

[1] F.Fiorillo and A.Novikov, "Power losses under sinusoidal,trapezoidal and distorted induction waveform," IEEE Trans.Magn., vol.26, no.5.

[2] C.Cester, A.Kedous-Lebouc, and B.Cornut, "Iron loss under practical working conditions of PWM powered induction motor," IEEE Trans. Magn., vol.33, no.5, pp.3766-3768. Sep.1977.

[3] Ruiming Fang and Rong Wang, "Iron losses calculation of the high speed and variable frequency conversion motor based on the hamonic analysis," Electric Machines and Control, vol.8, no 1, pp.25-27,2004.

[4] Pinglin Huang, Qiansheng Hu and Yang Cui, " Analytic calculation of the iron losses in the motor with the PWM inverter supply," Proceeding of the CSEE, vol 27,no.5, Apr.2007.

[5] A.Boglietti, A.Cavagnino, and M.Lazazzari, "Fast method for the iron loss prediction in inverter fed induction motors," IEEE Trans. Ind. Appl., vol.46, no.2, Mar. Apr. 2010.

[6] A.Boglietti, Andrea Cavagnino, and Dan M.lonel, "A general model to predict the iron losses in PWM inverter-fed induction motors," IEEE Trans.Ind.Appl., vol.46, no.5, Sep/Oct. 2010.

[7] Haisen Zhao, Yingli Luo and Xiaofang Liu, "Analysis on the iron losses distribution of asynchronous motors in no-load condition based on time-stepping finite element method," Proceedings of the CSEE, vol.30,no.30,pp. 99-106,2010.
[8] Emad Dlala and Antero Arkkio, "A general model for investigating the effects of the frequency converter on the magnetic iron losses of a squirrel-cage induction motor,” IEEE Trans. Magn., vol.45, no.9, Sep. 2009.

[9] Zbigiew Gmyrek, Aldo Beglietti, and Andrea Cavagnino, "Estimation of iron losses in induction motors: calculation method, results, and analysis," IEEE Trans. Ind. Electron, vol.57, no.1, Jan.2010.

[10] G.Bertotti, "General properties of power losses in soft ferromagnetic materials," IEEE Trans.Magn., vol.24, pp.621-630, Jan.1988.

[11] Shikun Chen, Motor design, Mechanical press,2000.

[12] Aldo Boglirtti,Andrea Cavagnino,Mario Lazzari,and Michele Pastorelli, "Predicting iron losses in soft magnetic Materials with Arbitrary voltage supply: an engineering approach," IEEE Trans. Magn., vol.39, no.2, Mar. 2003.

[13] F iorillo,A Novikov, “An Improved approach to power losses in magnetic laminations under nonsinusoidal induction waveform," IEEE Trans. Magn., 1990, 26(5): 2904-2910.

[14] Rotary motors standards compilation for introduction motor, Beijing: Standards Press of China, 2003.

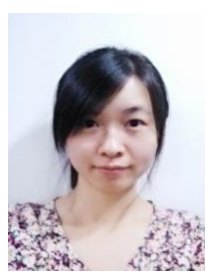

Hai-rong Wang received the B.S. degree from Jiangsu University, China. She is a currently M.S. degree student in the College of Electrical Engineering, Zhejiang University, China. Her research interests are the design and analysis of the inverter-fed induction motor.

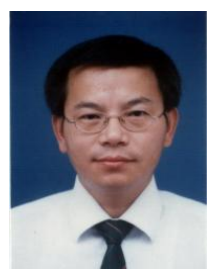

Jian-hua Wu received the B.S. degree from Nanjing University of Aeronautics and Astronautics, China, and the M.S. and Ph.D. degrees from Huazhong University of Science and Technology, China, in 1983, 1991 and 1994, respectively, all in electrical engineering. From 1983 to 1989, he was with Guiyang Electric Company as a Design Engineer. Since 2005, he was a professor in the College of Electrical Engineering, Zhejiang University, China. His research interests are electric machine design and drives, including switched reluctance motors, permanent magnet machines for electric vehicle applications. He developed the motor design software Visual EMCAD, which is widely used in China. He is serving as the member of Electrical Steel of Chinese Society for Metals, the member of Small-power Machine committee of China Electrotechnical Society, and the member of Standardization Administration of China. 